\title{
Suppression of SOX18 by siRNA inhibits cell growth and invasion of breast cancer cells
}

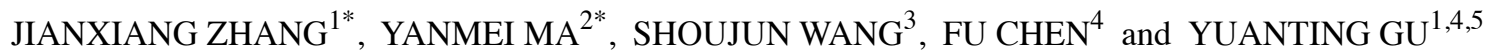 \\ Departments of ${ }^{1}$ General Surgery, ${ }^{2}$ Gastroenterology, ${ }^{3}$ Endocrinology, ${ }^{4}$ Integrated TCM and Western Medicine, \\ ${ }^{5}$ Breast Surgery, the First Affiliated Hospital of Zhengzhou University, Zhengzhou, Henan 450052, P.R. China
}

Received December 19, 2015; Accepted January 27, 2016

DOI: $10.3892 / o r .2016 .4746$

\begin{abstract}
Breast cancer is the most common malignancy in women around the world, and its incidence and mortality rates are still rising. An increasing number of studies have reported that SOX18 plays an important role in various cancers. However, the role of SOX18 in breast cancer remains poorly understood. In this study, we aimed to investigate the biological role and potential molecular mechanism of SOX18 in breast cancer. We found that the mRNA and protein expression levels of SOX18 were prevalently and significantly overexpressed in human breast cancer cell lines. Next, we performed loss-of-function experiments by transfection of two breast cancer cell lines, BT-474 and MCF-7, with SOX18 small interfering RNAs (siRNA). Results showed that SOX18 siRNA transfection significantly suppressed mRNA and protein expression of SOX18 in breast cancer cells. Furthermore, knockdown of SOX18 significantly inhibited cell proliferation and invasion, but promoted apoptosis in breast cancer cells. Importantly, several oncogenic proteins, including the Ras homolog gene family member A (RhoA), platelet-derived growth factor B (PDGFB), Insulin-like growth factor 1 receptor (IGF-1R), and matrix metalloproteinase-7 (MMP-7), were markedly decreased by SOX18 siRNA. Taken together, the results of our study suggest that knockdown of SOX18 inhibits breast cancer cell growth and invasion, possibly by downregulating downstream oncogenic proteins, providing novel insights into the development of breast cancer therapy through targeting of SOX18.
\end{abstract}

Correspondence to: Dr Yuanting Gu, Department of Integrated TCM and Western Medicine, the First Affiliated Hospital of Zhengzhou University, 1 Jianshe East Road, Zhengzhou, Henan 450052, P.R. China E-mail: yuantinggu@163.com

${ }^{*}$ Contributed equally

Key words: SOX18, siRNA, cell growth, invasion, human breast cancer cells

\section{Introduction}

Breast cancer is the most common malignancy in women around the world, and its incidence and mortality rates are increasing $(1,2)$. While surgery, radiotherapy, chemotherapy, hormone and/or biological methods are available clinical therapies for breast cancer, their therapeutic efficacy is still limited. Furthermore, the detailed pathogenesis of breast cancer is still unclear. Therefore, it is of great importance to gain a better understanding of the molecular mechanisms underlying breast cancer pathogenesis, which will help to identify an effective and specific molecular target for the development of novel and promising therapeutic strategies for breast cancer.

The SOX genes, located on the sex-determining region of the $\mathrm{Y}$ chromosome, are a highly conserved family of genes encoding various transcription factors. All family members share a high-mobility group (HMG-box) DNA-binding domain $(3,4)$. According to their HMG-box homology, the SOX family is divided into ten groups (A-J) (4-7). SOX18, a member of group F (SOX F), affects vascularization, neolymphangiogenesis, and tumor growth. SOX18 mutations are characterized by defective blood and lymphatic vessel formation, resulting in hypotrichosis-lymphodema-teleangiectasia syndrome (8-10). In addition, loss of function of SOX18 results in vascular and coat anomalies in ragged ( $\mathrm{Ra}$ ) mutant mice (11). Furthermore, SOX18 overexpression has recently been detected in several cancer-derived cell lines, including those from melanoma, hepatic carcinoma, and breast, gastric, lung, and pancreatic cancers (12-15). However, mechanistic insight into how SOX18 exerts its function in human breast cancer cells is still very limited.

Considering the important role of SOX18 in tumorigenesis and tumor progression, we investigated the functional role of SOX18 in breast cancer and explored the potential underlying mechanism of SOX18 in regulating breast cancer cell proliferation and invasion. We found that the mRNA and protein levels of SOX18 in human breast cancer cells were significantly increased, as compared with normal human breast epithelial cells. Then, by siRNA-mediated silencing of SOX18 in two breast cancer cell lines, BT474 and MCF-7, we demonstrated that SOX18 was involved in the regulation of cell proliferation, apoptosis, and invasion. Moreover, we found that SOX18 was associated with the regulation of several tumorigenic genes. Taken together, the results of our study provide evidence that 
SOX18 is a novel and promising molecular target for human breast cancer therapy.

\section{Materials and methods}

Cell culture. Human breast cancer cell lines, including BT-474, MCF-7, Hs578T, T-47D, and SK-BR-3, and the normal human breast epithelial cell line, MCF-10 were from the Cell Bank of the Shanghai Institutes for Biological Sciences, Chinese Academy of Sciences (Shanghai, China). MCF-10A cells were maintained in Dulbecco's modified Eagle's medium: F12 (DMEM: F12) medium supplemented with 5\% horse serum (Hyclone, Logan, UT, USA), $10 \mu \mathrm{g} / \mathrm{ml}$ insulin (Sigma-Aldrich, St. Louis, MO, USA), $100 \mathrm{ng} / \mathrm{ml}$ cholera toxin (Sigma-Aldrich), $20 \mathrm{ng} / \mathrm{ml}$ epidermal growth factor (EGF; Peprotech, Rocky Hill, NJ, USA), $0.5 \mu \mathrm{g} / \mathrm{ml}$ hydrocortisone (Sigma-Aldrich), $100 \mathrm{U} / \mathrm{ml}$ penicillin, and $100 \mathrm{mg} / \mathrm{ml}$ streptomycin. All other cell lines (human breast cancer cell lines) were grown in RPMI-1640 medium containing $10 \%$ fetal bovine serum (FBS; Gibco, Rockville, MD, USA), $100 \mathrm{U} / \mathrm{ml}$ penicillin, and $100 \mathrm{mg} / \mathrm{ml}$ streptomycin. These cell lines were maintained in a humidified incubator with $5 \% \mathrm{CO}_{2}$ at $37^{\circ} \mathrm{C}$.

Silencing of SOX18 by small interfering RNA (siRNA). siRNAs directed against either human SOX18 or negative control (NC) were purchased from Ambion (Austin, TX, USA). BT-474 and MCF-7 cells were grown in 6-well plates and transfected with SOX18 siRNA or NC (at a final concentration, $125 \mathrm{nM}$ ) using Lipofectamine 2000 (Invitrogen, Carlsbad, CA, USA), according to the manufacturer's instructions. At $48 \mathrm{~h}$ after transfection, cells were harvested for RT-PCR or western blot analyses.

$C C K-8$ assay. As described in detail previously (16), cell proliferation was assessed using the Cell Counting Kit-8 (CCK-8) (Beyotime, Nantong, China) method. Briefly, cells were seeded onto 96-well culture plates, and then transfected with SOX18 siRNA, or negative control (NC) using Lipofectamine 2000 according to manufacturer's instructions. At $48 \mathrm{~h}$ after siRNA transfection, CCK-8 solution was added to each well and incubated for $2 \mathrm{~h}$, and the absorbance was read at $450 \mathrm{~nm}$. The assay was performed in triplicate and repeated three times.

Protein extraction and western blotting. Total protein from treated and untreated BT-474 and MCF-7 cells was extracted using RIPA lysis buffer containing phenylmethylsulfonyl fluoride (PMSF). Protein concentrations were determined using the bicinchoninic acid (BCA) protein assay kit (Boster Biology Co., Wuhan, China). Equal amounts of protein were separated on SDS-polyacrylamide gels and electrotransferred to a PVDF (polyvinylidene fluoride) membrane. Membranes were blocked with $5 \%$ skim milk for $1 \mathrm{~h}$ at room temperature, and probed at $4^{\circ} \mathrm{C}$ overnight with primary antibodies. The appropriate secondary antibody was applied at room temperature for $1 \mathrm{~h}$. An ECL detection method (Pierce Biotechnology, Rockford, IL, USA) was subsequently used to visualize the protein band of interest. Densitometric analysis was performed using ImageJ software. Primary antibodies were purchased from the following companies: i) SOX18, RhoA, PDGFB, IGF1R and MMP7 (Santa Cruz
Table I. The primer sequences of PCR.

\begin{tabular}{ll}
\hline Primer & \multicolumn{1}{c}{ Sequence } \\
\hline$\beta$-actin & F: 5'-GCGCGGCTACAGCTTCA-3' \\
& R: 5'-TCTCCTTAATGTCACGCACGAT-3' \\
SOX18 & F: 5'-CGCGTGTATGTTTGGTTC-3' \\
& R: 5'-ATGTAACCCTGGCAACTC-3' \\
Bcl-2 & F: 5'- ATGTGTGTGGAGAGCGTCAACC-3' \\
& R: 5'- GCATCCCAGCCTCCGTTATC-3' \\
Bax & F: 5'-CCTTTTCTACTTTGCCAGCAAAC-3' \\
& R: 5'- GAGGCCGTCCCAACCAC-3' \\
RhoA & F: 5'-GAGTGTTCAGCAAAGACCAAAG-3' \\
& R: 5'-TTGCAGCAAGGTTTCACAAG-3' \\
PDGFB & F: 5'-CTCGATCCGCTCCTTTGATG-3' \\
& R: 5'-AGGAAGTTGGCGTTGGTG-3' \\
IGF1R & F: 5'-GAGCCTCCTGTGAAAGTG-3' \\
& R: 5'-GCATCCTGCCCATCATAC-3' \\
MMP-7 & F: 5'-GAGTGCCAGATGTTGCAGAA-3' \\
& R: 5 AAATGCAGGGGGATCTCTTT-3' \\
\hline
\end{tabular}

Biotechnology, Santa Cruz, CA, USA); ii) Bcl-2, Bax and $\beta$-actin (ProteinTech, Chicago, IL, USA).

Reverse transcription and real-time PCR (RT-PCR). Total RNA was extracted from treated and untreated cells using TRIzol reagent (Invitrogen) according to the manufacturer's protocol. cDNA was then synthesized using the PrimeScript RT reagent kit (Takara, Dalian, China) according to the manufacturer's instructions. Next, real-time PCR was performed using the LightCycler 480 and SYBR green master mix (Roche Diagnostics Ltd., Lewes, UK). $\beta$-actin served as an internal control. Results were normalized to the endogenous control ( $\beta$-actin). All RT-PCR amplifications were performed in triplicate. Fold changes were calculated in relation to reference control cDNA as previously described (17). The sequences of PCR primers for SOX18, RhoA, PDGFB, IGF1R, MMP7, $\mathrm{Bcl}-2$, Bax, and $\beta$-actin are listed in Table I.

Cell invasion assay. As described in detail previously (18), transwell insert assays were used to assess BT-474 and MCF-7 cell invasion ability. Briefly, for the invasion assay, siRNAtransfected cells in serum-free RPMI-1640 were seeded in the upper chambers of Matrigel-coated Transwell plates. To the lower chamber was added RPMI-1640 containing 10\% FBS $(600 \mu \mathrm{l})$ as a chemotactic factor. All of the Transwell chambers were then incubated at $37^{\circ} \mathrm{C}$ for $48 \mathrm{~h}$. Each subclone was seeded in triplicate. The migrated cells were observed under a Leica inverted microscope (Deerfield, IL, USA) and counted.

Caspase-3 activity assay. The caspase- 3 colorimetric assay is based on the hydrolysis of the peptide substrate acetyl-AspGlu-Val-Asp-p-nitroanilide (Ac-DEVD-pNA) by caspase-3, resulting in the release of the p-nitroaniline (pNA) moiety. 


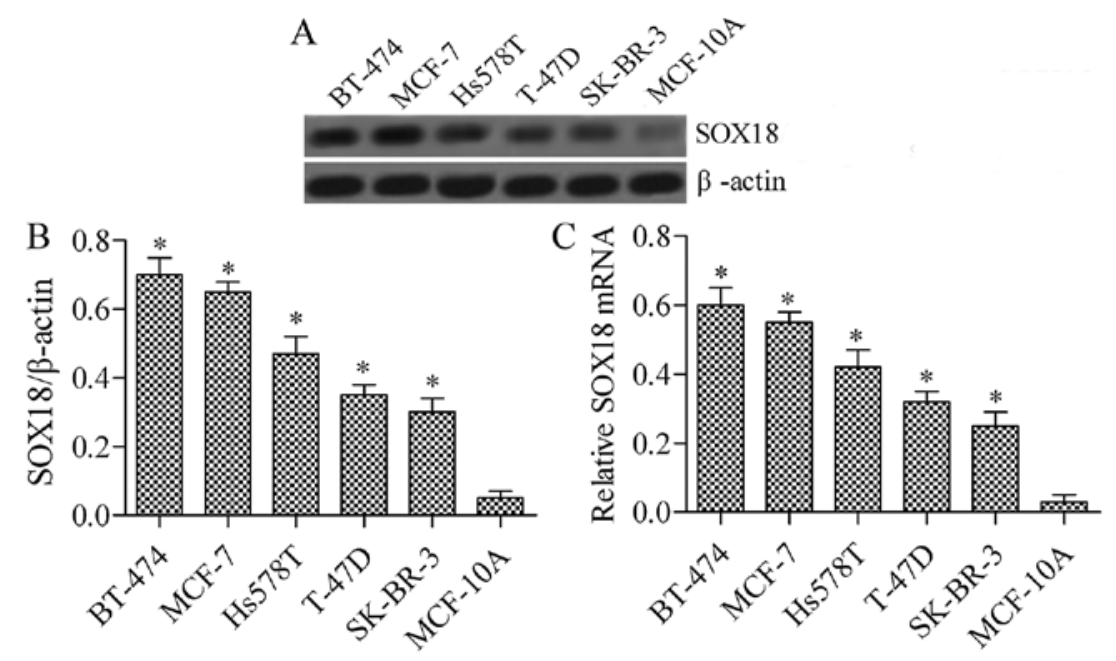

Figure 1. SOX18 is highly expressed in human breast cancer lines. The protein (A) and mRNA (C) expression of SOX18 was analyzed by western blot and RT PCR analysis, respectively. (B) The relative protein expression of SOX18 was analyzed by ImageJ software. Data are based on at least 3 independent experiments and are shown as mean $\pm \mathrm{SD}\left({ }^{*} \mathrm{P}<0.05\right.$ as compared with MCF-10A).

A
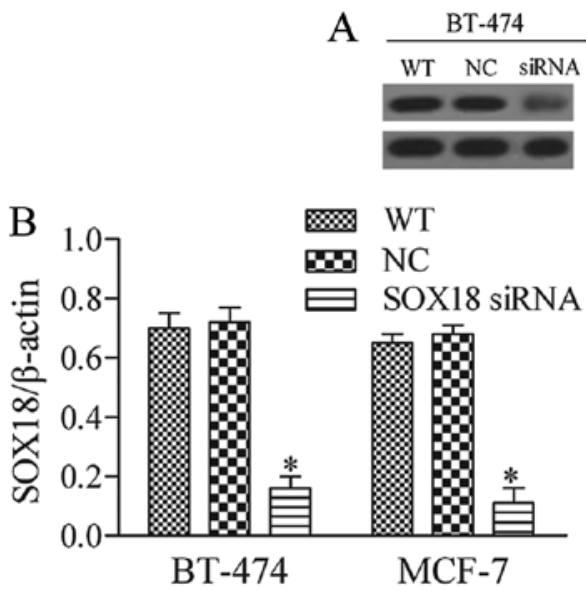
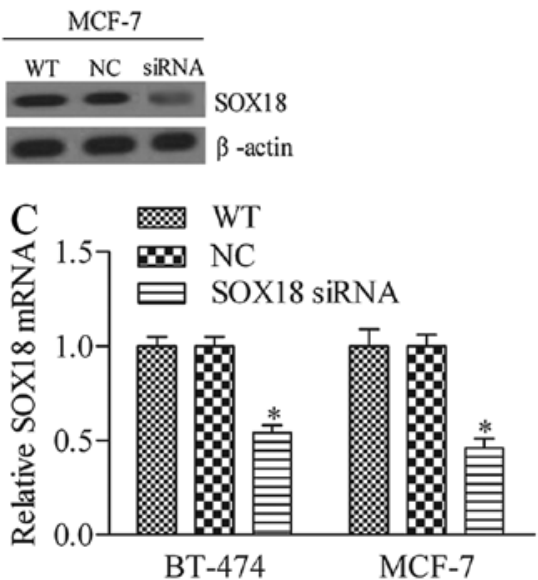

Figure 2. The silencing effect of SOX18-siRNA was evaluated in BT-474 and MCF-7 cells. The protein (A) and mRNA (C) expression level of SOX18 was analyzed by western blot and RT-PCR analysis, respectively. (B) The relative protein expression of SOX18 was analyzed by ImageJ software. WT, wild-type cells; NC, cells transfected with NC siRNA; SOX18 siRNA, cells transfected with SOX18-siRNA. Data are based on at least 3 independent experiments and are shown as mean $\pm \mathrm{SD}\left({ }^{*} \mathrm{P}<0.05\right.$ as compared with $\left.\mathrm{NC}\right)$.

pNA has a high absorbance at $405 \mathrm{~nm}$. Cell lysates were prepared using the Caspase-3 activity kit (EMD Millipore Corp., Billerica, MA, USA). The concentration of pNA released from the substrate is calculated from the absorbance values at $405 \mathrm{~nm}$. The rest of the detailed procedure was performed according to the manufacturer's instructions. This assay was performed in triplicate and repeated three times.

Statistical analysis. Data are summarized as mean \pm SD from at least three independent experiments. Statistical analysis was carried out using SPSS 17.0 software. Statistical differences were processed using one-way analysis of variance (ANOVA). A P-value of $<0.05$ was considered to be statistically significant.

\section{Results}

SOX18 is highly expressed in various human breast cancer cell lines. To investigate the function of SOX18 in human breast cancer cell lines, we evaluated its expression in four breast cancer cell lines (BT-474, MCF-7, Hs578T, T-47D, and SK-BR-3) and a normal human breast epithelial cell line (MCF-10A) using RT-PCR and western blotting. As shown in Fig. 1, the expression of SOX18 was significantly upregulated in breast cancer cell lines when compared with that of matched normal human breast epithelial cells, both at the protein (Fig. 1A) and mRNA expression levels (Fig. 1B). The data revealed that SOX18 is overexpressed in breast cancer cell lines, indicating that increased SOX18 protein expression is clearly involved in human breast cancer development.

Silencing of SOX18 by RNAi. To investigate the potential function of SOX18, the breast cancer cell lines, BT-474 and MCF-7 were selected for the RNAi experiment and transfected with one siRNA targeting human SOX18 (SOX18 siRNA) and a negative control (NC) siRNA. The silencing efficiency of the siRNA on SOX18 expression was then detected by western blot and RT-PCR analysis. Our results showed that SOX18 siRNA 


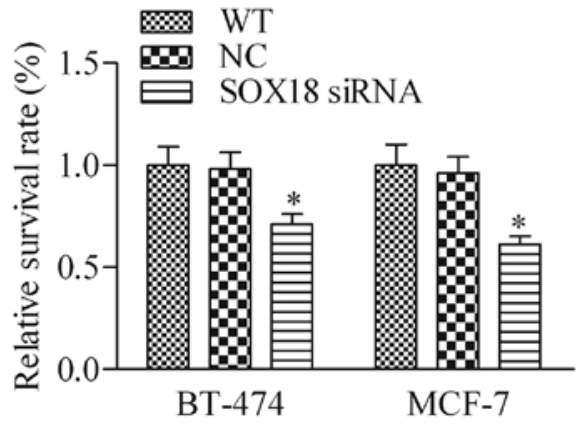

Figure 3. SOX18 knockdown inhibits human breast cancer cell proliferation. Results of the CCK- 8 assay performed in WT, NC and SOX18 siRNA cells. Data are based on at least 3 independent experiments and are shown as mean $\pm \mathrm{SD}\left({ }^{*} \mathrm{P}<0.05\right.$ as compared with $\left.\mathrm{NC}\right)$.

was able to efficiently and significantly suppress endogenous SOX18 expression in BT-474 and MCF-7 cells (Fig. 2A and B).

SOX18 knockdown inhibits human breast cancer cell proliferation. To test whether the silencing effect of SOX18 suppresses the proliferation of human breast cancer cells, BT-474 and MCF-7, the CCK-8 assay was performed. As shown in Fig. 3, cell proliferation of BT-474 and MCF-7 transfected with SOX18 siRNA was notably impaired when compared to the corresponding WT and NC cells. These results suggest that knockdown of SOX18 represses breast cancer cell proliferation.

Silencing of SOX18 in human breast cancer induces cell apoptosis. To further investigate the role of SXO18 in breast cancer cells, we next detected the effect of SOX18 silencing on breast cancer cell apoptosis. The results showed that knockdown of SOX18 significantly increased the expression of Bax and the activity of caspase-3 (Fig. 4A-C) in both BT-474 and MCF-7 cells. Furthermore, the protein expression level of $\mathrm{Bcl}-2$, an anti-apoptotic protein, was markedly decreased by SOX18 siRNA transfection. These results imply that knockdown of SOX18 promotes breast cancer cell apoptosis.
Silencing of SOX18 affects cell invasion in human breast cancer cells. To further investigate the biological role of SOX18 in breast cancer cells, we detected the effect of SOX18 siRNA on breast cancer cell invasion using the Transwell invasion assay. As shown in Fig. 5, the number of invaded cells in SOX18 siRNA-knockdown cells was significantly decreased in BT-474 and MCF-7 cells when compared with that of the WT and NC cells, suggesting that depletion of SOX18 markedly decreased the cell invasive ability of breast cancer cells.

Silencing of SOX18 in human breast cancer cells modulates the $M R N A$ and protein expression of RhoA, PDGFB, IGFIR, and MMP-7. To explore the potential underlying molecular basis of SOX18 in regulating breast cancer cell proliferation and invasion, we examined the expression of several oncogenic proteins, including RhoA, PDGFB, IGF1R and MMP-7 by western blot analysis and RT-PCR. Results showed that both protein (Fig. 6A) and mRNA (Fig. 6B) expression levels of these detected genes were markedly decreased after inhibition of SOX18 expression in BT-474 cells in comparison with control cells. Furthermore, similar data were observed using MCF-7 cells (Fig. 6C and D). These data suggest that SOX18 is an important transcription factor in breast cancer that modulates the expression of several oncogenic proteins.

\section{Discussion}

It is now clear that SOX genes encoding transcription factors are involved in embryonic development and oncogenesis (19). While the role and functions of SOX18 in various cancers are proundly reseached, the specific molecular functions of SOX18 in human breast cancer remain obscure. Here, we evaluated SOX18 expression in human breast cancer cell lines (BT-474, MCF-7, Hs578T, T-47D, and SK-BR-3) using RT-PCR and western blot analysis, and we found that SOX18 was highly expressed in breast cancer cell lines. Furthermore, knockdown of SOX18 by SOX18 siRNA suppressed cell proliferation and invasion of breast cancer cells, but promoted breast cancer cell apoptosis. Most importantly, several
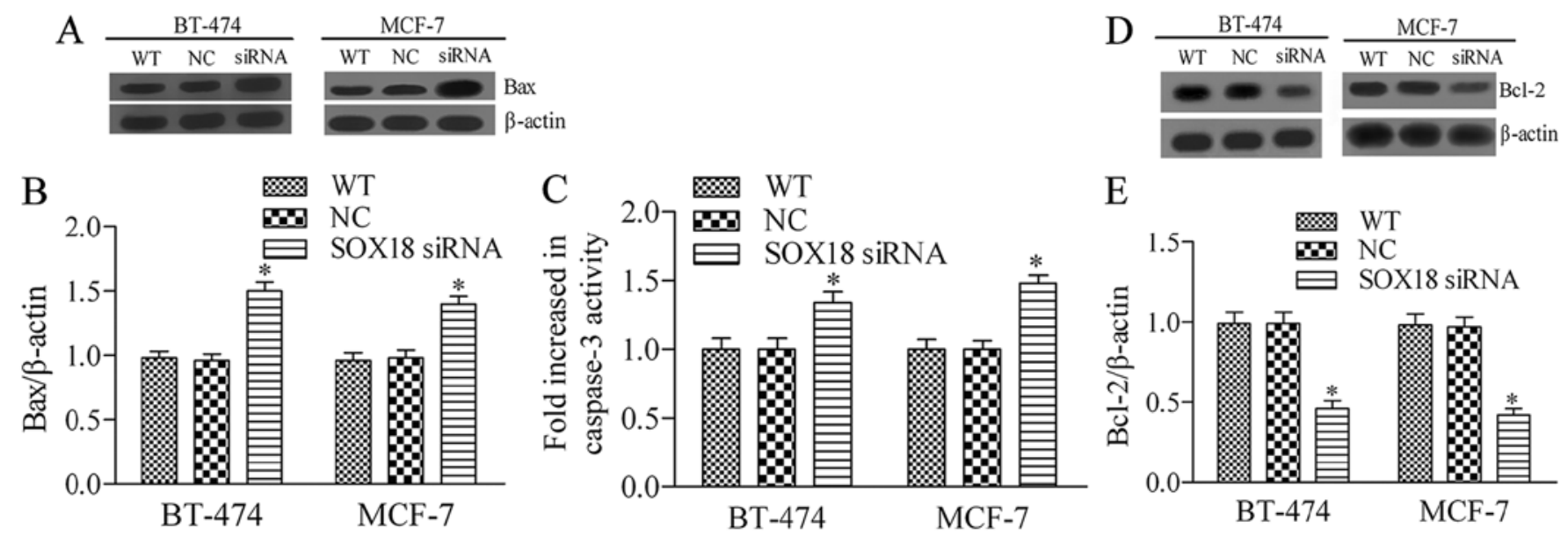

Figure 4. SOX18 knockdown induces cell apoptosis. (A) The protein expression of Bcl-2 in different transfected cells were detected by western blot analysis. (B) The relative protein expression of Bax was analyzed by ImageJ software. (C) The caspase-3 activity was detected in different cell groups using a commercial kit. (D) The protein expression of Bcl-2 in different transfected cells were detected by western blot analysis. (E) The relative protein expression of Bcl-2 was analyzed by ImageJ software. Data are based on at least 3 independent experiments and are shown as mean \pm SD ("P<0.05 as compared with NC). 


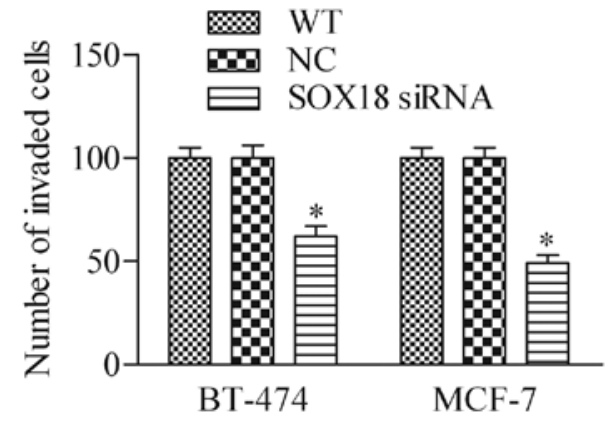

Figure 5. The silencing of SOX18 inhibits breast cancer cell invasion. Cell invasion was detected using Matrigel-coated Transwell chambers. Data are based on at least 3 independent experiments and are shown as mean $\pm \mathrm{SD}$ $\left({ }^{*} \mathrm{P}<0.05\right.$ as compared with NC).

oncogenic proteins, including RhoA, PDGFB, IGF1R, and MMP-7, were found to be regulated by SOX18. These results suggested that SOX18 was a critical regulator involved in human breast cancer.

Previous studies showed that SOX18 mRNA was expressed in pancreatic and breast cancer cells (13); in nonsmall cell lung cancer, SOX18 expression in mRNA and protein was significantly lower than in non-malignant lung tissue (12); Also, in ovarian cancer, SOX18 expression was detected in the cell nuclei as well as the cytoplasm using immunohistochemical methods (20). In the current study, the expression level of SOX18 mRNA and protein was significantly upregulated in human breast cancer cell lines when compared with a normal human breast epithelial cell line (Fig. 1A), which is consistent with the results obtained by immunohistochemistry showing that SOX18 was rarely expressed in non-malignant breast duct cells and frequently in invasive ductal breast carcinoma (21). Taken together, these findings suggest that SOX18 may serve as a novel oncogene and a potential therapeutic molecular target.

Previous studies have suggested the promoting effect of SOX18 on cell proliferation of vascular smooth muscle cells (22) and MCF-7 breast cancer cells (15). In line with these findings, knockdown of SOX18 in human breast cancer cells significantly impaired cell proliferation (Fig. 3). Moreover, we assessed the apoptotic function of SOX18 in SOX18 siRNA-treated breast cancer cells (Fig. 4A). Our data showed that the silencing of SOX18 significantly downregulated the expression of Bcl-2 and increased the activity of caspase-3 and expression of Bax in BT-474 and MCF-7 cells (Fig. 4), which might have contributed to the inhibition of proliferation in SOX18-knockdown cells.

In addition, the expression of SOX18 is mainly involved in tumor metastatic processes in lung and gastric cancer, where it plays an important role in regulating vascular formation and degradation of extracellular matrix tumor metastasis $(23,24)$. Consistent with these studies, we found that SOX18 siRNA treatment significantly decreased the invasive capabilities of breast cancer cells (Fig. 5), suggesting that tumor metastasis can be inhibited by SOX18 silencing in human breast cancer cells.

To elucidate the underlying mechanisms involved in cell proliferation, apoptosis and invasion induced by SOX18 silencing, we investigated the expression of several downstream signaling molecules of SOX18, including RhoA, PDGFB, IGF1R, and MMP-7, in SOX18 siRNA-knockdown breast cancer cells. RhoA, a small GTP-binding protein, has been reported to be associated with the occurrence, invasion, and metastasis of various tumors (25-27). PDGFB, a plateletderived growth factor, is a member of the PDGF family (PDGFA, B, C, and D) that is involved in multiple tumor-
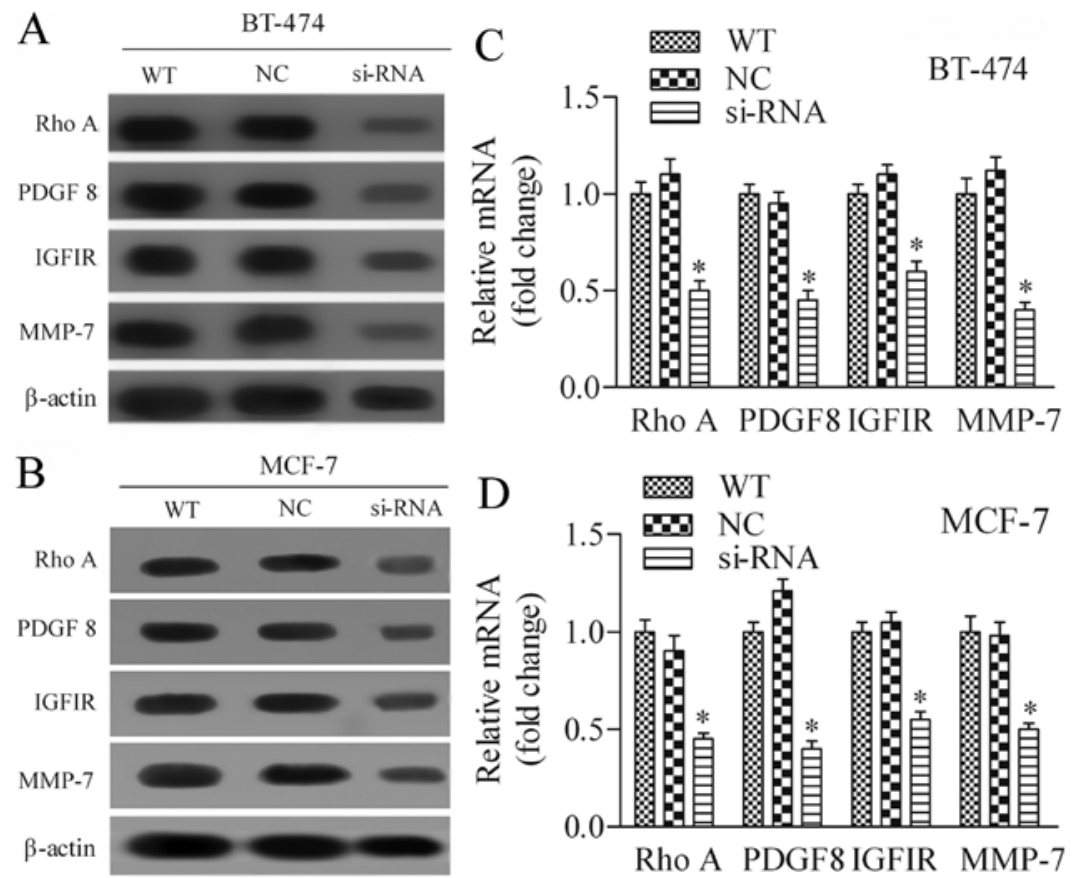

Figure 6. The effect of SOX18 gene silencing on the expression of RhoA, PDGFB, IGF1R and MMP-7. Western blot analysis of protein expression levels of RhoA, PDGFB, IGF1R and MMP-7 in BT-474 (A) and MCF-7 (C) cells. RT-PCR analysis of mRNA expression levels of $\mathrm{f}$ RhoA, PDGFB, IGF1R and MMP-7 in BT-474 (B) and MCF-7 (D) cells. Data are shown as mean \pm SD ("P<0.05 as compared with NC). 
associated processes, including tumor growth and metastasis (autocrine or paracrine) (28), tumor angiogenesis (29), and tumor fibroblasts (30). IGF1R is reported to be overexpressed in some types of human cancer, including lung, breast, pancreatic, prostate and glioma cancers (31-36). Moreover, IGF1R has been confirmed to play critical roles in multiple biological processes of tumor diseases, including malignant transformation, proliferation, anti-apoptosis, vascularization, and invasion (37). MMP-7 can cleave plasminogen and collagen XVIII to generate angiostatin and a $28 \mathrm{kDa}$ endostatin-spanning fragment, respectively (38). Previous studies have also suggested that SOX18 RNAi significantly downregulated the expression of detected genes in SOX18 siRNA-knockdown hepatocellular carcinoma cells (14) and in human endothelial cells (39). Our findings further proved that the expression of detected genes is significantly downregulated in SOX18 siRNA-treated breast cancer cells (Fig. 6), indicating that tumor progression can be inhibited by SOX18 silencing.

Interestingly, SOX18 expression also plays a crucial role in vascularization and lymphangiogenesis. Previous studies showed that vascular cell growth was inhibited by antisense SOX18 in endothelial cells and vascular smooth muscle cells (22); the expression of dominant-negative SOX18 in human umbilical vein endothelial cells impaired capillary tube formation (15). Additionally, knockdown of SOX18 selectively impaired lymphatic sprouting, resulted in defective lymphatic thoracic duct formation, and caused lymphedema (40). SOX18 expression is not responsible for the maintenance of lymphatic identity in the normal organism, whereas under pathological conditions, such as tumor growth, loss of SOX18 function impairs tumor-induced angiogenesis and lymphangiogenesis and decreases cancer cell metastasis (41). However, knowledge of whether knockdown of SOX18 expression decreases cancer metastasis through inhibition of angiogenesis and lymphangiogenesis in breast cancer would be required for further research.

In conclusion, this study showed for the first time that SOX18 silencing by siRNA inhibited proliferation and invasion and promoted apoptosis in human breast cancer cell lines in vitro. Furthermore, our findings showed that knockdown of SOX18 significantly downregulated the expression of associated tumorigenic genes (RhoA, PDGFB, IGF1R, and MMP-7) in SOX18 siRNA-knockdown breast cancer cells. Our results suggest that SOX18 is a promising therapeutic molecular target for the treatment of breast cancer.

\section{References}

1. Anaya-Ruiz M and Perez-Santos M: Innovation status of gene therapy for breast cancer. Asian Pac J Cancer Prev 16: 4133-4136, 2015.

2. Zhang GQ, He C, Tao L and Liu F: Role of DJ-1 siRNA in reverse sensitivity of breast cancer cells to chemotherapy and its possible mechanism. Int J Clin Exp Pathol 8: 6944-6951, 2015.

3. Harley VR, Lovell-Badge R and Goodfellow PN: Definition of a consensus DNA binding site for SRY. Nucleic Acids Res 22: 1500-1501, 1994.

4. Wegner M: From head to toes: The multiple facets of Sox proteins. Nucleic Acids Res 27: 1409-1420, 1999.

5. Dunn TL, Mynett-Johnson L, Wright EM, Hosking BM, Koopman PA and Muscat GE: Sequence and expression of Sox-18 encoding a new HMG-box transcription factor. Gene 161: $223-225,1995$.
6. Kanai Y, Kanai-Azuma M, Noce T, Saido TC, Shiroishi T, Hayashi Y and Yazaki K: Identification of two Sox17 messenger RNA isoforms, with and without the high mobility group box region, and their differential expression in mouse spermatogenesis. J Cell Biol 133: 667-681, 1996.

7. Taniguchi K, Hiraoka Y, Ogawa M, Sakai Y, Kido S and Aiso S: Isolation and characterization of a mouse SRY-related cDNA, mSox7. Biochim Biophys Acta 1445: 225-231, 1999.

8. Downes M, François M, Ferguson C, Parton RG and Koopman P: Vascular defects in a mouse model of hypotrichosis-lymphedematelangiectasia syndrome indicate a role for SOX18 in blood vessel maturation. Hum Mol Genet 18: 2839-2850, 2009.

9. François M, Caprini A, Hosking B, Orsenigo F, Wilhelm D, Browne C, Paavonen K, Karnezis T, Shayan R, Downes M, et al: Sox 18 induces development of the lymphatic vasculature in mice. Nature 456: 643-647, 2008.

10. Irrthum A, Devriendt K, Chitayat D, Matthijs G, Glade C, Steijlen PM, Fryns JP, Van Steensel MA and Vikkula M: Mutations in the transcription factor gene SOX18 underlie recessive and dominant forms of hypotrichosis-lymphedematelangiectasia. Am J Hum Genet 72: 1470-1478, 2003.

11. Pennisi D, Gardner J, Chambers D, Hosking B, Peters J, Muscat G, Abbott C and Koopman P: Mutations in Sox18 underlie cardiovascular and hair follicle defects in ragged mice. Nat Genet 24: 434-437, 2000.

12. Jethon A, Pula B, Olbromski M, Werynska B, MuszczynskaBernhard B, Witkiewicz W, Dziegiel P and Podhorska-Okolow M: Prognostic significance of SOX18 expression in non-small cell lung cancer. Int J Oncol 46: 123-132, 2015.

13. Saitoh T and Katoh M: Expression of human SOX18 in normal tissues and tumors. Int J Mol Med 10: 339-344, 2002.

14. Wang G, Wei Z, Jia H, Zhao W, Yang G and Zhao H: Knockdown of SOX18 inhibits the proliferation, migration and invasion of hepatocellular carcinoma cells. Oncol Rep 34: 1121-1128, 2015.

15. Young N, Hahn CN, Poh A, Dong C, Wilhelm D, Olsson J, Muscat GE, Parsons P, Gamble JR and Koopman P: Effect of disrupted SOX18 transcription factor function on tumor growth, vascularization, and endothelial development. J Natl Cancer Inst 98: 1060-1067, 2006.

16. Di J, Huang H, Qu D, Tang J, Cao W, Lu Z, Cheng Q, Yang J, Bai J, Zhang Y, et al: Rap2B promotes proliferation, migration, and invasion of human breast cancer through calcium-related ERK1/2 signaling pathway. Sci Rep 5: 12363, 2015.

17. Livak KJ and Schmittgen TD: Analysis of relative gene expression data using real-time quantitative PCR and the 2(-Delta Delta C(T)) method. Methods 25: 402-408, 2001.

18. McGarry T, Veale DJ, Gao W, Orr C, Fearon U and Connolly M: Toll-like receptor 2 (TLR2) induces migration and invasive mechanisms in rheumatoid arthritis. Arthritis Res Ther 17: 153, 2015.

19. Castillo SD and Sanchez-Cespedes M: The SOX family of genes in cancer development: Biological relevance and opportunities for therapy. Expert Opin Ther Targets 16: 903-919, 2012.

20. Pula B, Kobierzycki C, Solinski D, Olbromski M, NowakMarkwitz E, Spaczynski M, Kedzia W, Zabel M and Dziegiel P: SOX18 expression predicts response to platinum-based chemotherapy in ovarian cancer. Anticancer Res 34: 4029-4037, 2014.

21. Pula B, Olbromski M, Wojnar A, Gomulkiewicz A, Witkiewicz W, Ugorski M, Dziegiel P and Podhorska-Okolow M: Impact of SOX18 expression in cancer cells and vessels on the outcome of invasive ductal breast carcinoma. Cell Oncol (Dordr) 36: 469-483, 2013.

22. García-Ramírez M, Martínez-González J, Juan-Babot JO, Rodríguez C and Badimon L: Transcription factor SOX18 is expressed in human coronary atherosclerotic lesions and regulates DNA synthesis and vascular cell growth. Arterioscler Thromb Vasc Biol 25: 2398-2403, 2005.

23. Azhikina T, Kozlova A, Skvortsov T and Sverdlov E: Heterogeneity and degree of TIMP4, GATA4, SOX18, and EGFL7 gene promoter methylation in non-small cell lung cancer and surrounding tissues. Cancer Genet 204: 492-500, 2011.

24. Ma LJ, Wang J, Deng L and Yu S: Expression of SOX18, VEGF-C and VEGFR-3 and their clinical significance in gastric carcinoma. J Clin Exp Pathol 29: 1310-1316, 2013.

25. Huang KH, Lan YT, Chen MH, Chao Y, Lo SS, Li AF, Wu CW, Chiou SH, Yang MH, Shyr YM, et al: The Correlation Between RhoA Expression and Clinicopathological Characteristics in Gastric Cancer Patients After Curative Surgery. World J Surg 39: 2289-2299, 2015. 
26. Li XR, Ji F, Ouyang J, Wu W, Qian LY and Yang KY: Overexpression of RhoA is associated with poor prognosis in hepatocellular carcinoma. Eur J Surg Oncol 32: 1130-1134, 2006.

27. Wang M, Wang XJ and Liu BR: Effect of shRNA targeted against RhoA on proliferation and migration of human colonic cancer cells. Int J Clin Exp Pathol 8: 7040-7044, 2015.

28. Kuzmanov A, Hopfer U, Marti P, Meyer-Schaller N, Yilmaz M and Christofori G: LIM-homeobox gene 2 promotes tumor growth and metastasis by inducing autocrine and paracrine PDGF-B signaling. Mol Oncol 8: 401-416, 2014.

29. Kryza T, Achard C, Parent C, Marchand-Adam S, GuillonMunos A, Iochmann S, Korkmaz B, Respaud R, Courty Y and Heuzé-Vourc'h N: Angiogenesis stimulated by human kallikreinrelated peptidase 12 acting via a platelet-derived growth factor B-dependent paracrine pathway. FASEB J 28: 740-751, 2014.

30. Pietras K, Sjöblom T, Rubin K, Heldin CH and Ostman A: PDGF receptors as cancer drug targets. Cancer Cell 3: 439-443, 2003.

31. Deng WY,Li N, Wan XB,Luo SX and Zhang YW: Phosphorylated insulin-like growth factor-1 receptor expression predicts poor prognosis of Chinese patients with gastric cancer. Med Oncol 31: $141,2014$.

32. Farabaugh SM, Boone DN and Lee AV: Role of IGF1R in breast cancer subtypes, stemness, and lineage differentiation. Front Endocrinol (Lausanne) 6: 59, 2015.

33. Furukawa J, Wraight CJ, Freier SM, Peralta E, Atley LM, Monia BP, Gleave ME and Cox ME: Antisense oligonucleotide targeting of insulin-like growth factor-1 receptor (IGF-1R) in prostate cancer. Prostate 70: 206-218, 2010.

34. Hirano H, Lopes MB, Laws ER Jr, Asakura T, Goto M, Carpenter JE, Karns LR and VandenBerg SR: Insulin-like growth factor-1 content and pattern of expression correlates with histopathologic grade in diffusely infiltrating astrocytomas. Neuro Oncol 1: 109-119, 1999.
35. Ning $\mathrm{XH}$, Wang YZ, Bai CM and Li J: Clinical significance of insulin-like growth factor-1 receptor in platinum-based chemotherapy for non-small cell lung cancer. Zhongguo Yi Xue Ke Xue Yuan Xue Bao 32: 366-370, 2010 (In Chinese).

36. Zhao S, Qiu Z, He J, Li L and Li W: Insulin-like growth factor receptor 1 (IGF1R) expression and survival in non-small cell lung cancer patients: A meta-analysis. Int J Clin Exp Pathol 7: 6694-6704, 2014

37. Pollak M: The insulin and insulin-like growth factor receptor family in neoplasia: An update. Nat Rev Cancer 12: 159-169, 2012.

38. Patterson BC and Sang QA: Angiostatin-converting enzyme activities of human matrilysin (MMP-7) and gelatinase B/ type IV collagenase (MMP-9). J Biol Chem 272: 28823-28825, 1997.

39. Hoeth M, Niederleithner H, Hofer-Warbinek R, Bilban M, Mayer H, Resch U, Lemberger C, Wagner O, Hofer E, Petzelbauer P, et al: The transcription factor SOX18 regulates the expression of matrix metalloproteinase 7 and guidance molecules in human endothelial cells. PLoS One 7: e30982, 2012.

40. Cermenati S, Moleri S, Neyt C, Bresciani E, Carra S, Grassini DR, Omini A, Goi M, Cotelli F, François M, et al: Sox18 genetically interacts with VegfC to regulate lymphangiogenesis in zebrafish. Arterioscler Thromb Vasc Biol 33: 1238-1247, 2013.

41. Duong T, Proulx ST, Luciani P, Leroux JC, Detmar M, Koopman P and Francois M: Genetic ablation of SOX18 function suppresses tumor lymphangiogenesis and metastasis of melanoma in mice. Cancer Res 72: 3105-3114, 2012. 